\title{
Topographic mapping of collagenous gastritis
}

\author{
Hugh J Freeman MD
}

HJ Freeman. Topographic mapping of collagenous gastritis. Can J Gastroenterol 2001;15(7):475-478. A 74-year-old woman was investigated for abdominal pain and diarrhea. Endoscopic examinations including biopsies of the stomach and colon demonstrated the typical subepithelial deposits characteristic of collagenous gastritis and collagenous colitis. Histochemical and ultrastructural methods confirmed the presence of collagen in the subepithelial deposits. The topographic distribution of these collagen deposits and their relationship to the inflammatory process in the stomach were then defined by endoscopic mapping and multiple site biopsies of the mucosa in the gastric body and antrum. These studies indicate that collagenous gastritis not only is distinctive, but also is a far more extensive and diffuse inflammatory process than has previously been appreciated.

Key Words: Collagen; Collagenous colitis; Collagenous gastritis; Collagenous sprue; Gastritis; Helicobacter pylori

\section{Cartographie topographique de la gastrite collagène}

RÉSUMÉ : Une femme de 74 ans est venue consulter pour des douleurs abdominales et de la diarrhée. Les examens endoscopiques, dont une biopsie de l'estomac et du côlon, ont révélé la présence de dépôts sousépithéliaux, caractéristiques de la gastrite et de la colite collagènes. Des analyses histo-chimiques et ultrastructurales ont confirmé la présence de collagène dans les dépôts sous-épithéliaux. La répartition topographique de ces dépôts de collagène et leur lien avec le processus inflammatoire dans l'estomac ont alors été définis par une cartographie endoscopique et de nombreuses biopsies de la muqueuse effectuées dans le corps de l'estomac et l'antre du pylore. Les examens ont mis en lumière le fait que la gastrite collagène constitue non seulement un état pathologique distinct mais aussi un processus inflammatoire beaucoup plus diffus que ce que l'on croyait initialement.
$\mathrm{I}^{\mathrm{n}}$

n 1989, a form of gastritis that was histopathologically characterized by trichrome-positive, subepithelial deposits in gastric biopsies was described (1). The entity was termed 'collagenous gastritis' because it appeared to be reminiscent of previously described changes in the small or large intestine of patients with collagenous sprue or collagenous colitis $(2-6)$. In the same year, two other reports described similar microscopic changes in the gastric mucosa $(7,8)$. In 1990, collagenous changes were described in gastric and duodenal mucosa from a patient with collagenous colitis (9), and in 1996, collagenous gastritis was reported in a patient with another form of microscopic colitis - lymphocytic colitis (10). Recent ultrastructural confirmation of haphazardly arranged collagen fibres in these gastric subepithelial deposits has been reported (11).
Although the histopathological features of collagenous gastritis are unique, its topographic distribution within the gastric mucosa has not been systematically defined. Some believe that the entity may be a focal reparative 'fibrotic' response, possibly related to a pre-existing ulcer. Others feel that the entity may be a more generalized or even systemic process because 'immune-mediated' or autoimmune features have been reported with collagenous gastritis (1) and it has been linked to microscopic forms of colitis (ie, collagenous and lymphocytic colitis) (9-11). In the present report, histological and ultrastructural studies confirmed the presence of collagenous gastritis and colitis. Then, systematic topographic mapping of the distribution of this gastric lesion demonstrated that it is a diffuse and far more extensive inflammatory process than has been previously appreciated.

Department of Medicine (Gastroenterology), University of British Columbia, Vancouver, British Columbia

Correspondence and reprints: Dr Hugh Freeman, ACU F-137, Gastroenterology, University of British Columbia Hospital, 2211 Wesbrook Mall, Vancouver, British Columbia V6T 1W5. Telephone 604-822-7216, fax 604-822-7236

Received for publication May 23, 2000. Accepted July 24, 2000 


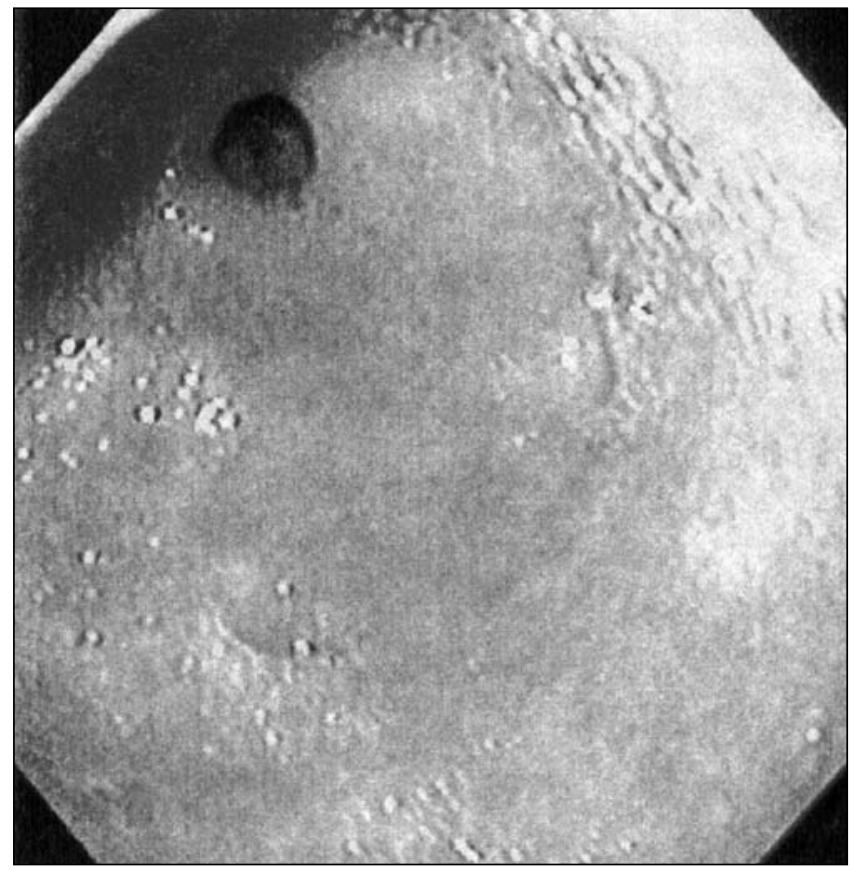

Figure 1) Endoscopic view of immediate prepyloric gastric antrum. Nonspecific erythema without ulceration, erosions or friability is present

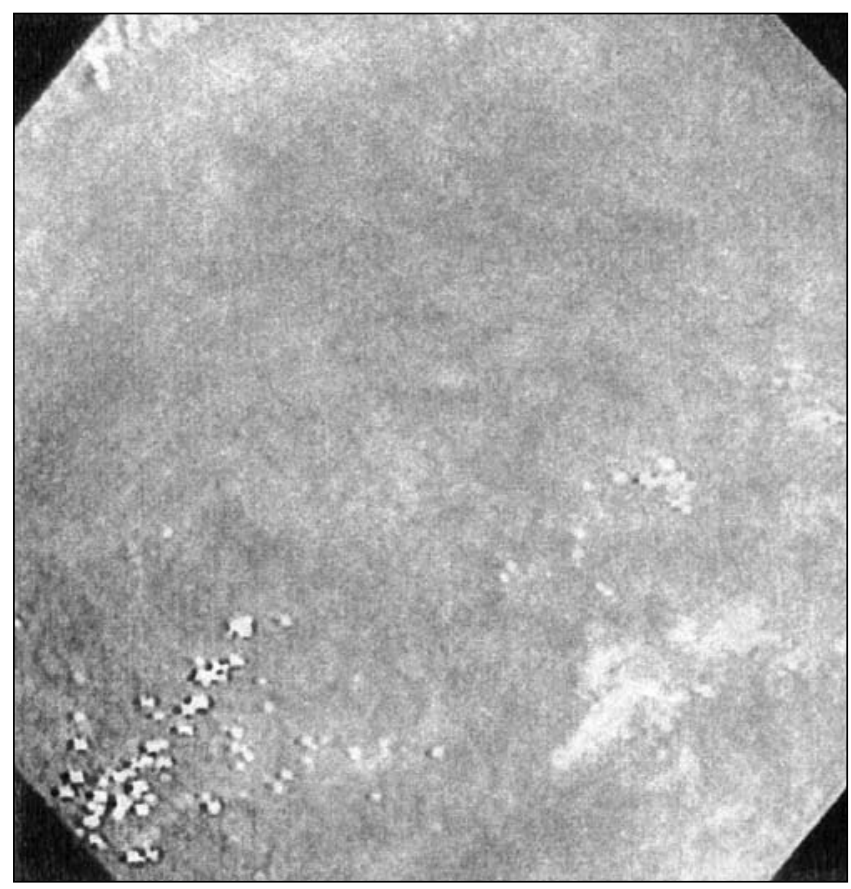

Figure 2) Endoscopic view of the greater curvature of the gastric antrum. Minimal erythema with an absence of the vascular pattern is evident

\section{CASE PRESENTATION}

A 74-year-old woman had persistent diarrhea and left-sided abdominal pain for three months. Fecal cultures and parasite examinations were negative. A flexible sigmoidoscopy and rectal biopsy revealed collagenous colitis, while a barium enema was normal. Blood tests including a hemogram, serum proteins, serum iron and iron-binding capacity were

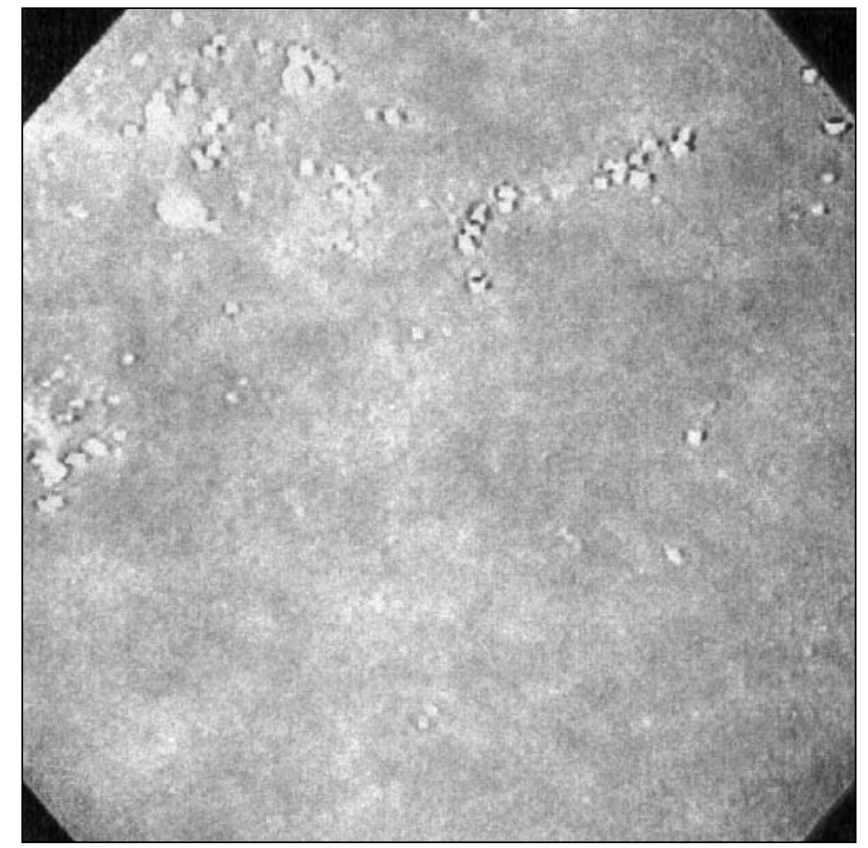

Figure 3) Endoscopic view of the greater curvature of the gastric antrum. Patchy areas of pallor are present with an absent vascular pattern

normal. The erythrocyte sedimentation rate was slightly elevated at $28 \mathrm{~mm} / \mathrm{h}$. Serological studies for neutrophil cytoplasmic autoantibodies were negative. Because of reports of celiac disease in collagenous colitis (12-14), an upper endoscopy was done. Although the small bowel appeared to be normal, the gastric antrum was diffusely abnormal with loss of vascular pattern, mucosal erythema and diffuse areas of mucosal pallor (Figures 1-3). All areas of the gastric antrum were involved. There were no ulcers or erosions. Similar changes were present in the gastric body mucosa, but the vascular pattern was more clearly discerned, particularly on the greater curve (Figure 4). Gastric biopsies showed collagenous gastritis (Figures 5,6), while small intestinal biopsies from sites in the duodenal bulb and descending duodenum were normal. Helicobacter pylori and other organisms were not detected. Ultrastructural studies of additional gastric and colonic biopsies confirmed that the subepithelial deposits contained collagen fibres with the typical periodic spacing of normally formed collagen. Topographic biopsy studies were then done (see below), and the patient was empirically administered omeprazole $20 \mathrm{mg}$ daily for 28 days; during treatment, her symptoms of abdominal pain and diarrhea resolved. Since completion of this treatment course, symptoms have not recurred. However, additional post-treatment gastric and colonic mucosal biopsies showed persistent subepithelial collagen deposits in both the stomach and colon.

\section{TOPOGRAPHIC BIOPSY STUDIES}

Topographic 'mapping' of the gastric antrum and body mucosa was done after obtaining informed consent. The stomach was arbitrarily divided into four portions with the incisura as the central landmark. Twenty biopsies were 


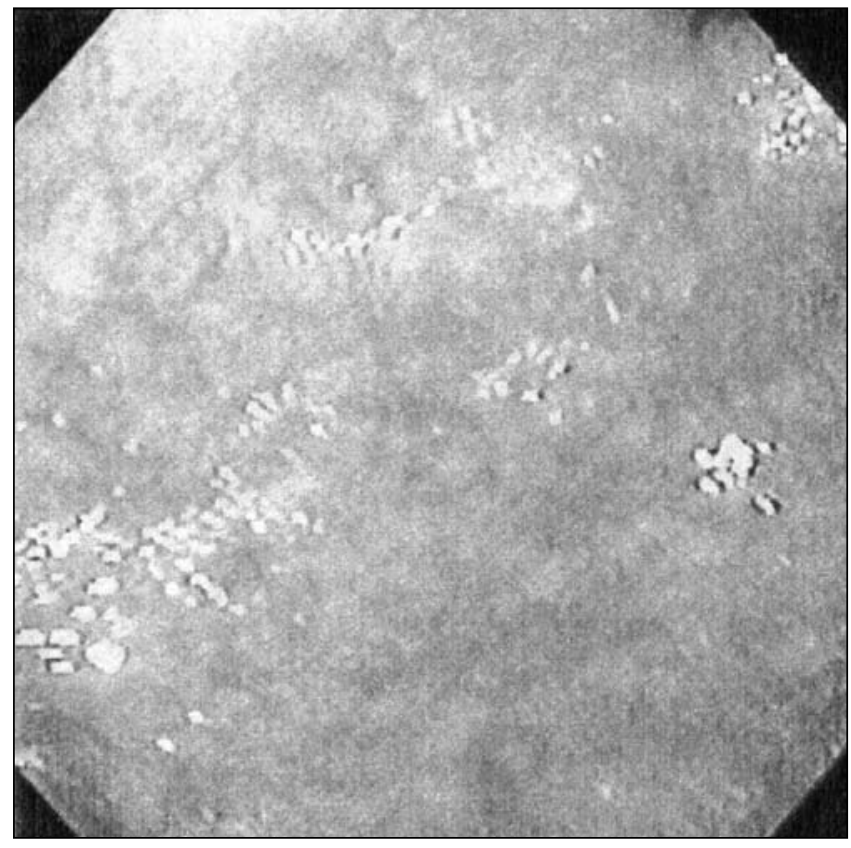

Figure 4) Endoscopic view of the gastric body opposite the incisura. Gastric mucosal vessels are visible

obtained - five from each resultant quadrant along the greater and lesser curvatures. Blinded histological evaluation of hematoxylin and eosin-stained sections (as well as trichrome-stained sections) revealed a mixed lymphocytic and neutrophilic infiltrate in each biopsy, with some gastric body and antral mucosal glandular atrophy. In addition, subepithelial deposits of collagen were present diffusely throughout the gastric antral biopsies and extended proximally to the 'transitional zone' with the gastric body. Additional small intestinal biopsies were normal. Following omeprazole treatment, another endoscopic study with multiple biopsies $(n=20)$ from sites identical to the pretreatment topographic biopsy sites were obtained. These biopsies showed an identical distribution of the gastric mucosal deposits of subepithelial collagen. However, the previously defined foci of polymorphonuclear leukocyte infiltration had completely resolved.

\section{DISCUSSION}

Collagenous gastritis was first described in 1989 (1). It appears to be an exceedingly rare entity; only seven cases have been described to date (1,7-11), including six in the English literature (Table 1), and one of these cases did not have subepithelial localization of collagen (9). Indeed, only two cases, including the present case (11), have provided confirmation of the suspected collagen material with ultrastructural evaluation using electron microscopy. This was not possible in the initial patient reported from our hospital because of the course of her illness (1) and was not reported in the other four cases $(7-10)$. In each patient evaluated to date, only a limited number of biopsies were obtained; in some of these, it was not clear whether single or multiple biopsies were evaluated and whether the pathological

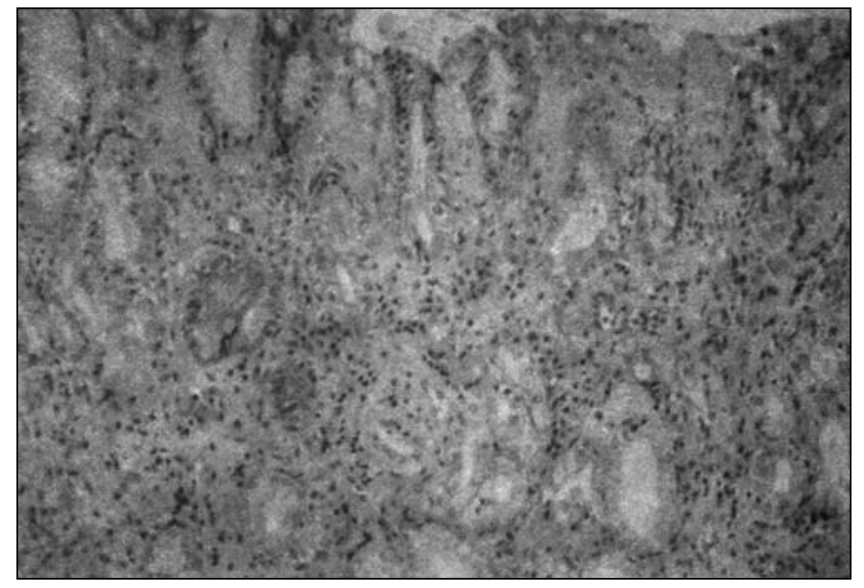

Figure 5) Gastric antral mucosal biopsy showing minimal diffuse inflammatory infiltrate with slight gastric antral glandular atrophy. Some epithelial cells appear to be sloughed from the lamina propria surface. In addition, there is a diffuse and distinct subepithelial band of eosinophilic material that stains positive for trichrome

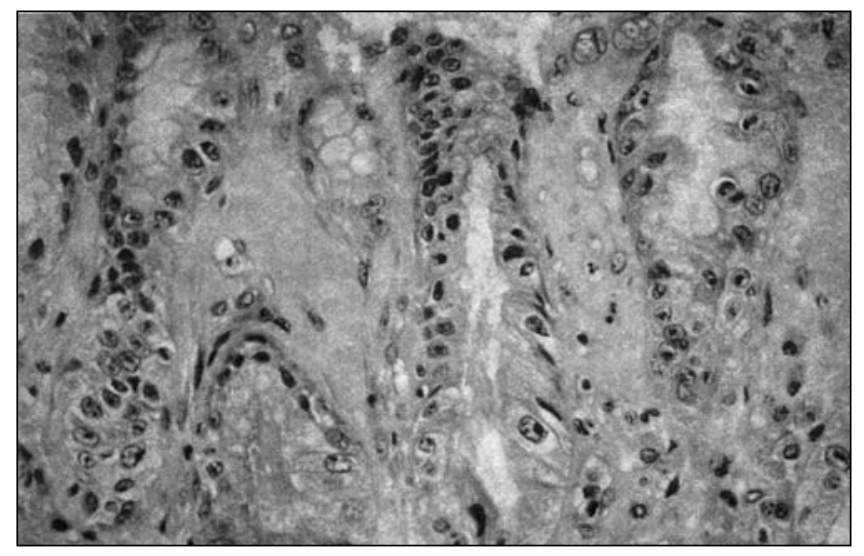

Figure 6) Same region of the gastric antrum at higher power showing subepithelial eosinophilic deposits. Electron microscopy confirmed the presence of collagen fibres. In addition, entrapped plasma cells and lymphocytes are present within the deposits, and neutrophilic leukocytes are evident in the surface epithelium

inflammatory process or the collagen deposits were distributed in a focal or diffuse manner. While erosions have been described only in a single patient with collagenous gastritis to date (7), a focal distribution of collagen might reflect the fibrotic reparative process involved with healing of a focal mucosal lesion, such as an ulcer or an erosion. In the present report, the gastric mucosa was systematically 'mapped' to determine the distribution of the inflammatory process along with the coexistent subepithelial collagen deposits. Endoscopic mapping of the gastric mucosa was also performed after a course of antisecretory therapy with omeprazole. The findings indicate that collagenous gastritis is a unique and far more extensive inflammatory process than is currently appreciated, and the deposition of subepithelial collagen in the present patient was diffusely distributed rather than localized to a specific site in the gastric mucosa. In this patient, antisecretory therapy appeared to reduce the 
TABLE 1

Reported cases of collagenous gastritis

\begin{tabular}{|c|c|c|c|c|c|}
\hline Author(s) (reference), year & Country & Age (years)/sex & Pathology & Collagenous colitis & Other \\
\hline Freeman et al (1), 1989 & Canada & $54 / \mathrm{F}$ & $\begin{array}{c}\text { Diffuse } \mathrm{AB} \text { gastritis and } \\
\text { glandular atrophy, focal } \\
\text { A collagen }\end{array}$ & No & $\begin{array}{c}\text { Sjogren's } \\
\text { syndrome, hyposplenism, } \\
\text { gastroparesis, } \\
\text { hypoproteinemia }\end{array}$ \\
\hline Colletti and Trainer (7), 1989 & United States & $15 / F$ & $\begin{array}{c}\text { Erosive AB } \\
\text { gastritis and glandular } \\
\text { atrophy, focal B collagen }\end{array}$ & No & \\
\hline Borchard and Niederau (8), 1989 & Germany & $67 / F$ & AB gastritis, focal collagen* & No & \\
\hline Stolte et al (9), 1990 & Germany & $75 / \mathrm{F}$ & $\begin{array}{c}\mathrm{AB} \text { gastritis, } \\
\text { collagen* (not subepithelial) }\end{array}$ & Yes & \\
\hline Groisman et al (10), 1996 & United States & $35 / F$ & $\mathrm{AB}$ gastritis, collagen & No & Lymphocytic colitis \\
\hline Pulimood et al (11), 1999 & India & $20 / M$ & $\begin{array}{c}\text { AB gastritis, } \\
\text { glandular atrophy, collagen }\end{array}$ & Yes & \\
\hline Freeman, $1999^{\ddagger}$ & Canada & $74 / F$ & $\begin{array}{l}\text { Diffuse AB gastritis, } \\
\text { glandular atrophy, } \\
\text { diffuse A collagen }\end{array}$ & Yes & \\
\hline
\end{tabular}

${ }^{*}$ Small bowel (duodenal) collagen also present with villous atrophy. No collagen detected in the small bowel of other reported cases; ${ }^{+}$Ultrastructural con-

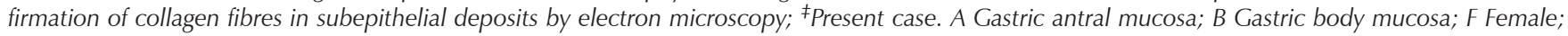
M Male

acute polymorphonuclear inflammatory cellular infiltrate in the gastric antrum and gastric body, but had no significant detectable morphological effect on the the subepithelial collagen deposits. The macroscopic changes visualized during the endoscopic study were not specific, similar to the lack of specificity noted for the endoscopic changes with collagen deposition elsewhere in the intestinal tract (6). The findings in this patient emphasize the importance of microscopic evaluation of visualized endoscopic findings. Although collagenous gastritis is very rare, a diagnosis should be readily accomplished in most routine pathology laboratories if multiple endoscopic biopsies are submitted by the endoscopist from different recorded sites within the gastric mucosa.

The pathogenesis of this inflammatory process remains obscure. Specific organisms such as $\mathrm{H}$ pylori or Gastrospirillum species have not been recorded in reports to date. However, there are descriptions of concurrent involvement with collagenous colitis $(10,11)$, as in the present case, as well as collagenous duodenitis $(9,10)$. This suggests that these disorders may be due to a more generalized and apparently distinct pangastrointestinal inflammatory process. Indeed, the association with other 'immune-mediated' disorders in the occasional patient (1) raises the possibility of a more systemic pathological process. Finally, a localized disorder of the pericryptal fibroblast has been previously suggested, particularly in collagenous colitis (15). Recently, ultrastructural evidence for activated pericryptal fibroblasts was reported in collagenous gastritis (11). Further studies, possibly exploring the metabolism of these cells in the production or breakdown of collagen, are needed.

In summary, collagenous gastritis is a distinctive form of gastritis. The gastric inflammatory process diffusely involves the stomach, while the typical subepithelial collagen deposits may be detected in some patients elsewhere in the intestinal tract. Multiple gastric biopsies at the time of endoscopic evaluation should readily permit diagnosis, even if endoscopic changes are limited. Further studies are needed to elucidate the pathogenesis and treatment of this intriguing disorder.

\section{REFERENCES}

1. Freeman HJ, Piercey JRA, Raine RJ. Collagenous gastritis. Can J Gastroenterol 1989;3:171-14.

2. Weinstein WM, Saunders DR, Tytgat GN, Rubin CE. Collagenous sprue. An unrecognized type of malabsorption. N Engl J Med 1970;283:1297-301.

3. Schein J. Syndrome of nontropical sprue with hither-to undescribed lesions of the intestine. Gastroenterology 1947;8:438-60.

4. Freeman HJ, Weinstein WM, Shnitka TK, Wensel RH, Sartor VE. Watery diarrhea syndrome associated with a lesion of the colonic basement membrane-lamina propria interface. Ann R Coll Phys Surg Can 1976;9:45.

5. Lindstrom CG. "Collagenous colitis" with watery diarrhea - a new entity? Pathol Eur 1976;11:87-9.

6. Freeman HJ. Collagenous inflammatory mucosal diseases of the gastrointestinal tract. Can J Gastroenterol 1990;4:196-200.

7. Colletti RB, Trainer TD. Collagenous gastritis. Gastroenterology 1989;97:1552-5.

8. Borchard F, Niederau C. Kollagene gastroduodenitis. Dtsch Med Wochenschr 1989;114:1345.

9. Stolte M, Ritter M, Borchard F, Koch-Scherrer G. Collagenous gastroduodenitis on collagenous colitis. Endoscopy 1990;22:186-7.

10. Groisman GM, Meyers S, Harpaz N. Collagenous gastritis associated with lymphocytic colitis. J Clin Gastroenterol 1996;22:134-7.

11. Pulimood AB, Ramakrishna BS, Mathan MM. Collagenous gastritis and collagenous colitis: a report with sequential histological and ultrastructural findings. Gut 1999;44:881-5.

12. Hamilton I, Sanders S, Hopwood D, Bouchier IA. Collagenous colitis associated with small intestinal villous atrophy. Gut 1986;27:1394-8.

13. Eckstein RP, Dowsett JF, Riley JW. Collagenous enterocolitis. A case of collagenous colitis with involvement of the small intestine. Am J Gastroenterol 1988;83:767-71.

14. Wolber R, Owen D, Freeman HJ. Colonic lymphocytosis in patients with celiac sprue. Hum Pathol 1990;21:1092-6.

15. Hwang WS, Kelly JS, Shaffer EA, Hershfield NB. Collagenous colitis. A disease of the pericryptal fibroblast sheath? J Pathol 1986;149:33-4. 


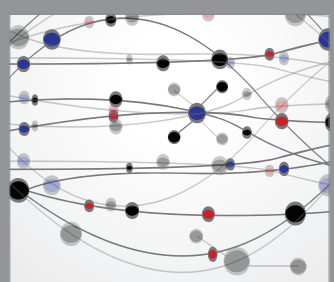

The Scientific World Journal
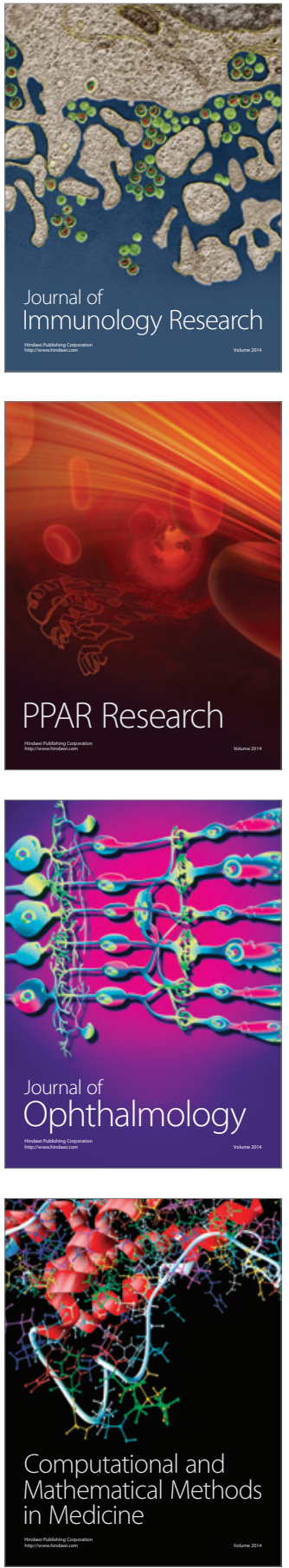

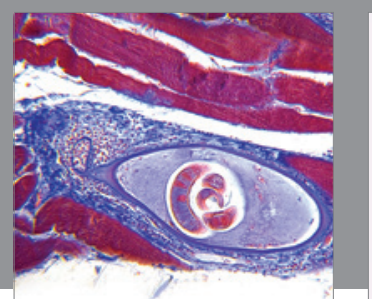

Gastroenterology Research and Practice

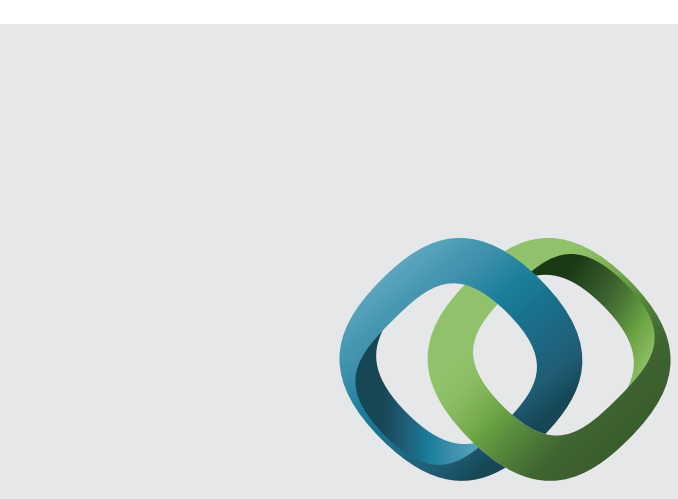

\section{Hindawi}

Submit your manuscripts at

http://www.hindawi.com
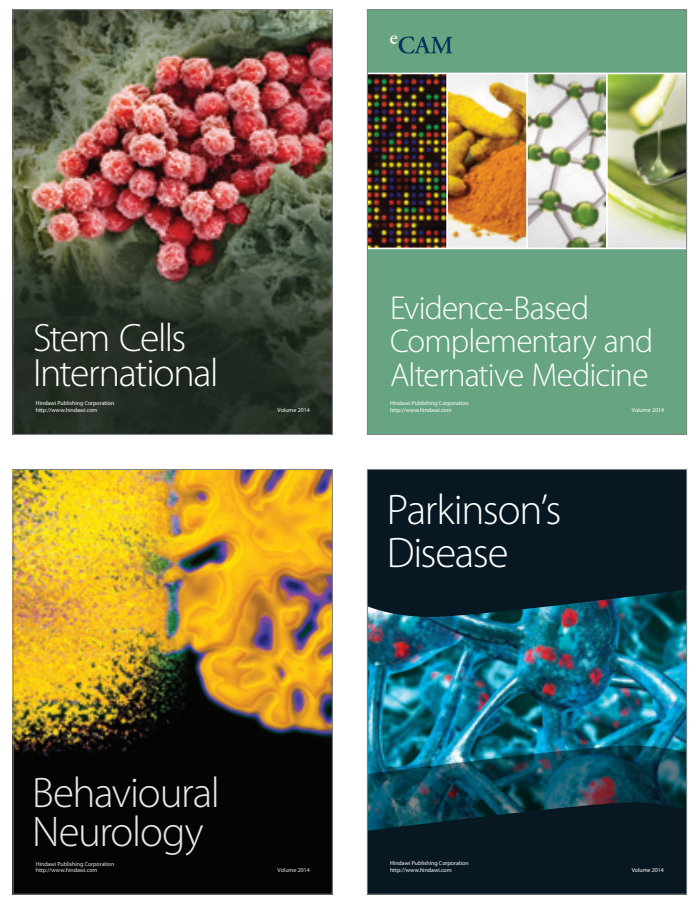
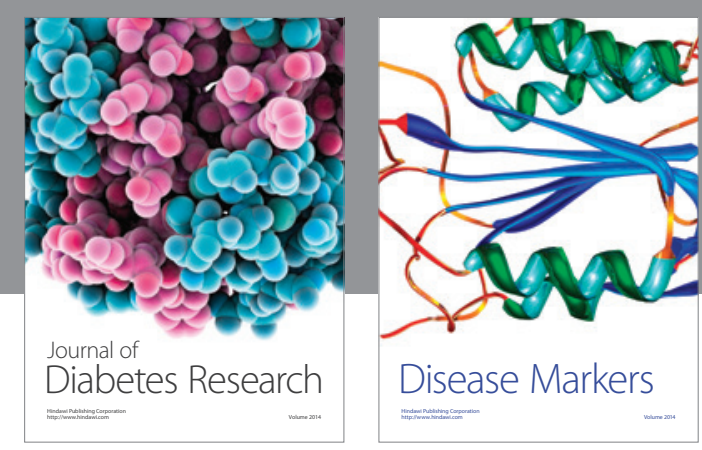

Disease Markers
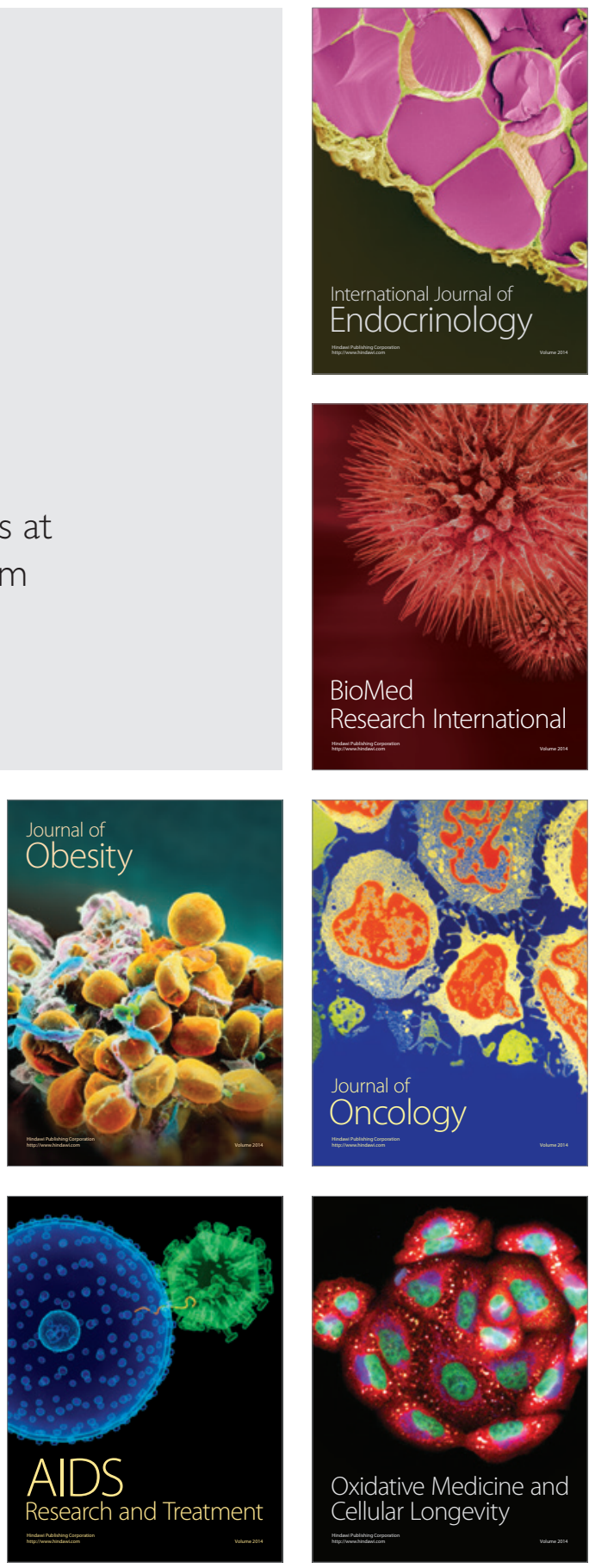